\title{
The Health and Well-being of Low Paying Jobs in Southern Africa: Case Study of Security Guards in Zambia
}

\author{
Esnart Mwaba Tayali \\ PhD Student in Work \\ Employment, and Organisation- University of Strathclyde
}

Kwesi Atta Sakyi

Head of Research

ZCAS University, Lusaka, Zambia

\begin{abstract}
As concerns for employee well-being across all sectors increase, security guards in Southern Africa and the rest of Africa at large attract less attention in human resource management. Well-being is pivotal for positive psychological feeling of workers, and also conducive for economic growth. Employee well-being has positive effects on company performance, profitability and growth. Therefore, employee well-being is a cardinal factor across the globe. Security guards, like any other employees, deserve decent conditions of service, which promote their overall well-being. Youths who lack sufficient funds to pursue tertiary education in universities end up undertaking the most affordable short courses in order to see them through employment, as they are desperate for incomes to sustain themselves and families. The commonest affordable short courses in Southern Africa include those found in jobs such as security guards, carpentry, tailoring, and cookery. Amongst the most affordable short courses, youths prefer security guard training due to its high job market demand. The health, safety, and quality of the physical environment, as well as the low subsistence wages for Security guards leave much to be desired. The labour standards of security guards in Africa are unthinkable, unsatisfactory and atrocious. This study aims at introducing essential recommendations in order to improve the well-being of security guards in southern Africa. The paper adopted a qualitative research approach by gathering information from security guards working in five different security firms in Zambia.
\end{abstract}

Key words: Well-being, Sub-Saharan Africa, Security guards, labour standards, Eudaimonia, Hedomia/Hedonism

\section{INTRODUCTION}

Despite making significant contributions to society and business, security guards in southern Africa are exposed to outrageous labour standards. As a result, this career is demeaned by society. The emotional, social, psychological health, and general well-being of security guards in southern Africa is in jeopardy. It is of utmost importance to urgently address the plight of security guards in order to promote rapid business and economic growth in southern African countries. The annual standard 
Tayali, E. M., \& Sakyi, K. A. (2020). The Health and Well-being of Low Paying Jobs in Southern Africa: Case Study of Security Guards in Zambia. Advances in Social Sciences Research Journal, 7(4) 229-247.

wage of a Zambian security guard is \$904 United States Dollars, at a monthly rate of \$75 USD or about one thousand three hundred and fifty kwacha (K1,350) (Zambia Daily Mail, 2012). This cannot sustain the living costs of an average person in Zambia (cf. JCTR).

The above observation on wages of security guards suggests that a security guard lives on $\$ 2.50$ USD a day. According to the UN (2017), a person living on $\$ 1.95$ per day lives under the poverty datum line. This income suggests that security guards live in extreme poverty. As a result, they struggle to fulfil the important basic needs such as food and decent shelter. Security guards in Zambia have no benefit packages. Even under these poor conditions, they go for several months without receiving their paltry monthly salary. Furthermore, the safety and physical working environments under which they operate are a threat to their overall well-being. According to the Zambia Daily Mail (2014), security guards are the most neglected workers in Zambia.

They work without the proper gear of boots, military fatigue uniforms and other security accessories such as batons, whistles, cell phones, panic-buttons, rain coats, and blankets. Security guards are mostly managed by micro-managers who show high levels of disrespect, discrimination, bullying, harassment and unethical behavior towards them. The poor and inhuman behavior of supervisors leads to job dissatisfaction on the part of the security guards. The guards have low bargaining power because of their economic vulnerability. It is therefore easy to hire and fire them. They have no voice in improving their harsh working conditions. They opt to have a dissatisfying job rather than to voice out their dissent and lose their employment, in the face of increasing financial hardships.

Security guards in Sub-Saharan Africa are denied of intra-mural welfare facilities which are the basic needs for an employee to be satisfied in order for them also to enjoy overall well-being. Without intra-mural welfare facilities, productivity is low (Suresh, 2015). Security guards need to be properly managed in order to give them social protection. In Zambia, as in every other country, human rights and the rule of law are enshrined in the constitution yet some employers cash in on the high levels of unemployment in the country to exploit workers. The labour laws are not fully observed by the security companies. According to the Zambia Daily Mail (2017), Security companies breach the minimum wage due to the high levels of corruption prevailing in Zambia.

\section{LITERATURE REVIEW}

The World Bank (2018) in their Zambia Country Systematic Diagnostic report noted that between 2000 and 2015, GDP growth in Zambia did not translate into poverty alleviation because the Zambian economy is not well-integrated in the regional hub supply chain. The report also noted that lack of competition was also one of the reasons for the gains of growth not filtering down to the grassroots. Thus, there was poverty inelasticity in the Zambian economy and low entry barriers to regional trade. The World Bank report also noted the lack of diversification in the Zambian economy as part of the weird economic phenomenon of growth without development. The highly centralised system of governance in Zambia could be a reason for the poverty-inelastic growth phenomenon. Observers also point to the fact of slow reaction to events by government due to bureaucratic hurdles and the political culture of high-power distance.

The World Bank noted that between 2004 and 2014, the economy grew by 7.4\% from mainly mining and agricultural activities, debt relief, and heavy investment in the social and services sectors. 
However, growth was still dampened by high population growth rate of $2.8 \%$ per annum. The World Bank (2018) noted the low returns or productivity in the service sector, the escalation of national debt, and lack of growth and development in rural areas as areas of concern in Zambia. Overall, these factors deepen and worsen the unemployment situation, and make it hard for employers to provide decent wages and decent working conditions.

According to Nyirenda \& Sikazwe (2003) the high rate of unemployment in Zambia is a result of pursuing the liberalization and privatization policies which the Zambian government embarked upon in the early 90s following the end of the one-party system and state-controlled regime that ended in 1991. Many people lost their jobs in the formal public sector because of the need to scale down the activities of state-run enterprises most of which were loss-making and heavily indebted (Nyirenda et al., 2003, pp. 3-4)

For example, from 1991 to 1997, employment in the public sector fell from 544,200 to 475,000 due to heavy retrenchments and redundancies declared in the state-run enterprises and also in the public services of government line ministries where external creditors asked the Zambian government to reduce the size of government machinery by laying off some workers. By the year 2000 , the public sector labour force was 476,347. The bleak labour market led to exploitation by employers in the private sector who took advantage of the scarcity of jobs to start paying low subsistence wages (Nyirenda et al., 2003) The deterioration of decent work conditions in Zambia today had its genesis from the early 90 s.

These poor working conditions are in contrast to ILO Conventions which guarantee industrial relations and right of workers to join and affiliate to trade unions for protection of their well-being. These rights are found under ILO Conventions No. 87 and 98 which Zambia ratified in 1996 (Nyirenda et al., 2003). These Conventions are meant to protect vulnerable people such as security guards who need equity in their industrial relations with employers (Nyirenda et al., 2003, p.6).

The ILO Convention allows government intervention where trade unions are absent or where they are weak. Government intervention is to ensure that minimum working standards are observed (Nyirenda et al., 2003) To all intents and purposes, trade unions are weak at the bargaining table, especially in a developing country such as Zambia with weak social and legal institutions and a weak economy. According to Nyirenda et al. (2003) the framework or legal basis of industrial relations in Zambia is Part 3 of the Constitution Article 21 Chapter 269 of the Laws as amended in Labour Relations Act, Employment Act, Minimum Wages and Children Act, and Factories Act.

The Act was amended in 1971 (Act No 36, 1971) in 1990 (Act No 36, 1990) in 1993 (Act No 27, 1993) and Employment Code Act 2019 No 23 of 2019. The Act provides for allowing formation of trade unions and associations where the employer employs not less than 25 employees, formation of Employers' associations and federations to provide platform and for a dialogue and collective bargaining wage and conditions of service negotiations in tripartite format, with representations from workers, employers, and government labour commissioners as arbiters and regulators. Trade union recognition is cardinal to the Act (Nyirenda et al., 2003)

According to Nyirenda et al. (2003) the State has residual powers to intervene in any trade dispute between employer and employees in order to ensure that workers well-being is protected from 
Tayali, E. M., \& Sakyi, K. A. (2020). The Health and Well-being of Low Paying Jobs in Southern Africa: Case Study of Security Guards in Zambia. Advances in Social Sciences Research Journal, 7(4) 229-247.

abuse and unfair treatment. Gough, Chigunta \& Langevang (2016) in their study which was done in one of the deprived areas of Lusaka, painted graphic details of unemployed youth who went about making a living from doing odd jobs to survive. They posited that high levels of poverty, rural-urban migration, rapid population growth and poor performance of the Zambian economy were some of the factors which worsened the plight of the youth in forcing them to take low-paying and indecent jobs.

In their findings, they observed that the youth wanted well-paying, decent and permanent jobs, preferably in the public sector but they could not find such job openings due to corruption and also their own lack of technical and professional skills which they lacked because they did not proceed far in their education. The author of this paper came across a contract for security guards signed between the UNO Zambia and a local security company called Armcor to supply guards for the UN. Interestingly, the security guards were being offered the low wages of 1,350 kwacha for day guards and 1,250 kwacha for night guards. However, these conditions in the contract were far better than most other security contracts where guards are not properly clothed or properly equipped (UN Zambia, 2012)

ILO Zambia (2019) noted that the labour participation rate in Zambia was weak at 76\% (quoting CSO, 2005). ILO (2019, p.11) noted that by 2015, Zambia still did not have Labour Market Information System (LMIS) to help in making informed decisions, and that Zambia was yet to pay a minimum wage that would be commensurate with the high cost of living in the country. ILO (2019) further observed that the 2017 Survey showed that youth account for $55 \%$ of the labour force with youth unemployment at 17\%. ILO (2019) also observed that half of the youth employed were in low-paying jobs.

From 2013 to 2016, ILO helped Zambia by embarking on a programme called Decent Work Country Programme (DWCP) by helping to provide decent paying jobs in the informal sector as a form of model of best practice. However, despite the best of intentions, such laudable programmes are not sustainable as they eventually fizzle out. The objective was to help formalize the informal sector. The Zambia Government complemented the effort by initiating the National Social Protection Policy under which there is the Social Cash Transfer programme to assist in alleviating poverty among identified vulnerable people such as the old people who are looking after HIV/AIDS orphans.

Most of such noble programmes often lack consistency and also funds to carry them through. It is to be noted that decent work requires having ergonomic or safe work environments, equity at the workplace in terms of having horizontal and vertical equity in pay structures, harmonization of salary structures to avoid wide discrepancies among employees, and opportunities for career growth and advancement, among others. The ILO report (2019, p.17) noted that even though the informal sector in Zambia employed $84 \%$ of the labour force, its contribution to GDP was low at $33 \%$, implying low levels of motivation, low productivity, underpayment of workers, exploitation and indecent working conditions.

The ILO recommended that the future of work in Zambia requires upgrading of skill sets, retraining, worker empowerment with technological skills, as the future knowledge workers will need soft people skills as well as ICT skills such as handling Big Data, Data Science, Artificial Intelligence, Internet of Things (IoT), Vehicle of Things in Smart Cities, among other skills. 
Zambia has a skills gap in the middle sector of Vocational training as artisans are lacking. This is why many school-leaving youth become unemployable and end up in low-paying jobs as security guards. The IMF (2006) also recommended that there should be fiscal as well as political decentralisation in Zambia to create space for the informal sector players to create jobs and also help rural areas to develop and take charge of their own development agenda.

Rapid decentralisation will lead to redistribution of income, poverty reduction and rapid economic growth through the principle of subsidiarity where local areas gain autonomy to attend to their own needs. In the Daily Nation Newspaper of May 19, 2015 it was reported that security guards in a known company were demanding the removal of their new boss because he was firing those who were complaining about the poor conditions of service. They were protesting that despite the national minimum wage having been set at 1200 kwacha, they were receiving 400 kwacha, far below the prescribed minimum wage. Such news make sad reading. However, many guards lack adequate knowledge with regard to market dynamics of demand and supply, and the requirements of legal contracts. Besides, the trade union everywhere in the world is weak following the death of the one party state or socialism. Workers also forget that productivity and performance improvement are criteria for negotiating for increased wages.

Valentine (2002, pp.10-11) carried out a study on the pay and conditions in the Zambian public sector on behalf of the Zambian Government. His study showed massive decline over time in real wages from 1975 to 2000, and also decline in real GDP as a result of many underlying factors during the same period from 1975 to 2000. These factors included the fall in copper prices on the global market, low productivity of workers due to demotivation, high labour turnover, lack of commitment of workers, lack of trust between managers and subordinates, weak accountability systems, poor quality of services performed, deviant behaviour, vandalism and poor work culture. Valentine (2002) noted that real per capita GDP fell from 100 in 1975 to 55 in 2000, and real minimum wages for civil servants during the same period fell from 100 to 15.

\section{IMPORTANCE OF SECURITY GUARDS}

A security guard is a person who is hired to safeguard or protect a property, an area or people either through indirect or direct observation (Dowd, 2018). Security guards though disdained by society in Southern Africa, play a significant role to protect businesses, banks, schools and all other important premises, facilities, and installations. Besides that, security guards also protect people from criminals.

A world without security guards would lack order and safety. Therefore, corroborating the wellbeing of security guards is pivotal to the success of businesses, banks, schools, and safety of people in general.

\section{Work and well-being}

Work has a major influence on human well-being as it gives a sense of self-worth and meaning to an individual. According to an evidence-based research review by Waddell (2006), work is good for an individual's well-being. This is because work is an important means through which economic resources are obtained. These economic resources are essential for meeting an individual's basic life needs and material well-being. Equally important, work plays a major role in meeting an individual's psychosocial and psychological needs. The economic gains from work also enable an 
Tayali, E. M., \& Sakyi, K. A. (2020). The Health and Well-being of Low Paying Jobs in Southern Africa: Case Study of Security Guards in Zambia. Advances in Social Sciences Research Journal, 7(4) 229-247.

individual to participate in society. Furthermore, work is essential to an individual's social role, status and identity. As a result, work has an influence on the well-being of an individual. Having a decent work profile is essential for an individual's well-being (Health \& Safety Authority, 2008).

\section{The Well-being Pyramid}

The Chartered Institute of Personal and Development (CIPD), developed a well-being pyramid in a quest to enhance health and well-being in Europe. The well-being pyramid includes three domains which must be used by an organisation in order to have a healthy workplace. In the Well-being pyramid, the bedrock for well-being include Culture, people management and leadership (CIPD, 2016). A fully integrated well-being approach in an organisation must constitute the three perspectives. An organisation needs to have a well-defined culture linked to the well-being of the people. Furthermore, there must be good leadership and people management in an organisation. A leadership with a heart for mankind, to care for the well-being of employees and promote wellbeing in all work aspects is a plus. Organisations must have a value-based leadership, with a clear Well-being strategy, clear objectives and mission statement as well as good corporate governance.

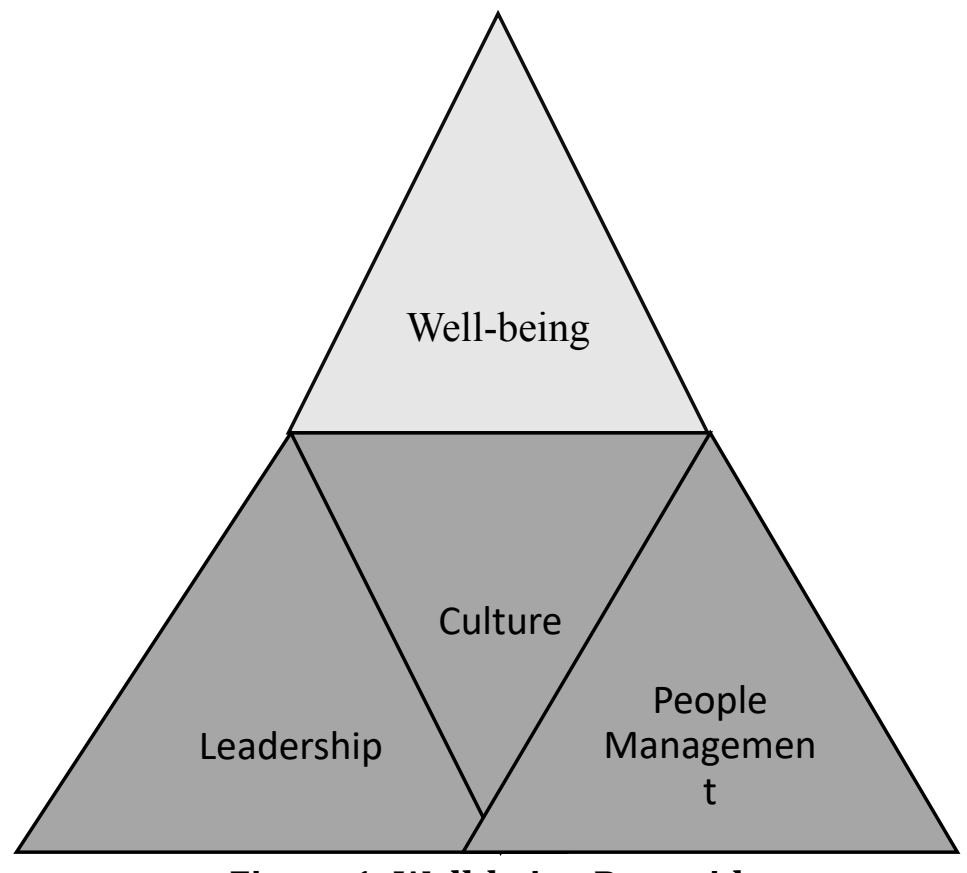

Figure 1: Well-being Pyramid

(Source: CIPD, 2016)

\section{METHODOLOGY}

The researcher of this study adopted a deductive research approach by supporting findings with empirical evidence and theories. She used a qualitative and exploratory approach to provide a fluent understanding of findings and the discussions

\section{Findings and Analysis}

\section{Understanding Well-being in the context of Security Guards}

Well-being is the state of being comfortable, happy, contented, successful and healthy (Chen et al., 2014). Well-being is a key component of positive psychology. Well-being at the workplace involves multiple aspects; these include the safety of the working environment, the quality of workplace 
facilities, among others (Huka, 2015). Workplace well-being also involves the overall satisfaction and happiness of an employee that results from having workplace facilities and a good working environment. Several aspects can facilitate health, well-being, and security of employees in SubSaharan Africa. According to the UN 2030 Agenda, every person should reap the benefits of prosperity and enjoy minimum standards of well-being.

The well-being of security guards is also a means through which their dependent families are freed from hunger and poverty. The well-being of security guards also is a means through which they are assured of a healthy lifestyle. Security guards in southern Africa are amongst the most vulnerable people and those deepest in poverty in southern Africa (Borgen project, 2018). Fostering minimum standards of well-being will help embrace the goals aimed at achieving overall well-being for all employees, especially the most vulnerable with little or no voice (Fisher, 2014).

However, it is imperative to recognize that such high goals of enhancing the overall health and wellbeing of security guards cannot be achieved without understanding the minimum standards of wellbeing as well as involving the major stakeholders.

The major stakeholder in this case is the government which needs to put in place the regulatory framework for the well-being of employees. Government oversight will force security firms to abide by the rules set by the government. These minimum standards of well-being should reflect social inclusion for security guards as that will aid to gain them the opportunities and resources necessary for them to participate fully in social and economic life, and to enjoy a standard of living that is considered normal in the society in which they live.

Furthermore, the minimum standards will guarantee a greater voice for security guards in matters which directly affect them in the workplace. This will enhance decision making and build their selfesteem. Equally important, the minimum standards which will be set will ensure that the most vulnerable employees such as security guards can exercise their fundamental rights.

\section{Analysis of Indicators for Well-being on Security guards}

There are a number of well-being indicators for employees (OECD, 2020). This study adopted seven indicators to determine the well-being of security guards in Zambia. The study analysed job satisfaction, how safe the employees feel in their job, employee life satisfaction as a result of work conditions, social support from society, social interaction with the society due to status and the voice employees have in society. Figure 2 depicts that the job strain for the security guards is high. Furthermore, the life satisfaction for the employees is low, equally they have little social support from society. These factors have an influence on their well-being. 
Tayali, E. M., \& Sakyi, K. A. (2020). The Health and Well-being of Low Paying Jobs in Southern Africa: Case Study of Security Guards in Zambia. Advances in Social Sciences Research Journal, 7(4) 229-247.

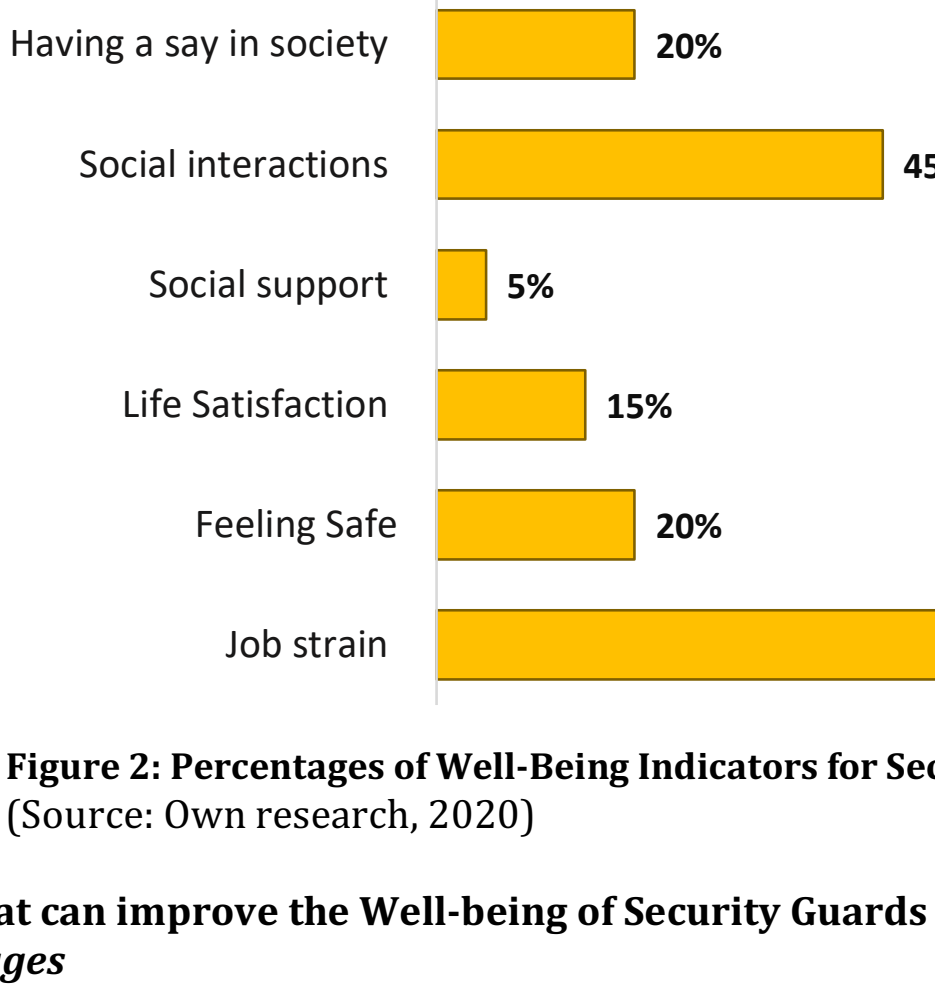

\section{Factors that can improve the Well-being of Security Guards Decent Wages}

A wage is an important factor for an employee in a workplace. An employee has many reasons to get into employment, amongst which include earning a wage to meet basic survival needs (Gunwan et al., 2015). Employees earn an income in order to fulfil the basic needs which include food, shelter, and clothing.

A wage must be decent enough to facilitate or fulfil the basic needs of an employee. Wages have an impact on employee well-being, productivity and economic growth (Simone, 2015). Security guards in Southern Africa earn on average, a monthly wage of $\$ 75$, living on $\$ 2.50$ a day.

Surprisingly UN Zambia and Armcor security company signed a contract for provision of comprehensive security, in this contract it was agreed that security guards are paid $\$ 75$ (Contract CS08, 2012).

This wage suggests that security guards live in abject poverty. Such a wage has caused social exclusion and vulnerability for security guards. They are not able to meet their basic requirements like food, shelter, drink, clothing and health facilities which are needed for human survival. Decent wages can bring about decent living (UN, 2018).

Governments need to impose minimum wages for security guards and ensure that security firms adhere to those standards. The purpose of having a minimum wage is to protect security guards from poor remuneration, and help ensure an equitable distribution and harmonization of wages for all employees. Furthermore, instituting a minimum wage helps in reducing inequalities, social exclusion, and it assists in overcoming poverty (ILO, 2012). 


\section{Risk, Overtime allowance and benefit packages}

Security guards are exposed to life-threatening situations which can lead to loss of life. For example, they work in high crime areas during the night, standing guard outside in open places where they are exposed to the public. Due to long hours of such risky exposure, they deserve risk allowance. Due to the non-social hours in which they work, security guards end up working more hours than they should work.

However, despite working more hours, they are not paid overtime. Security guards in Southern Africa go for several months working without a pay. Furthermore, security guards work under nonbenefit conditions. These factors are detrimental to the well-being of security guards. Figure 1 below gives a breakdown of what should constitute a sound package of emoluments that will guarantee well-being for security guards in Zambia. These forms of expectations can form the basis of providing them with decent packages in order to guarantee them decent living.

It must be pointed out though that long ago, Adam Smith, the Father of Economics observed that workers suffer from money illusion, and that it is not the size of their nominal income that mattered but rather their real income or their purchasing power of their income over goods and services. Therefore, security guards will need powerful lobbies and platforms to intervene on their behalf in order for them to have living wages, risk allowances, overtime allowances, cost of living allowances, and regular increment or upward adjustment of their wages in line with inflationary trends.

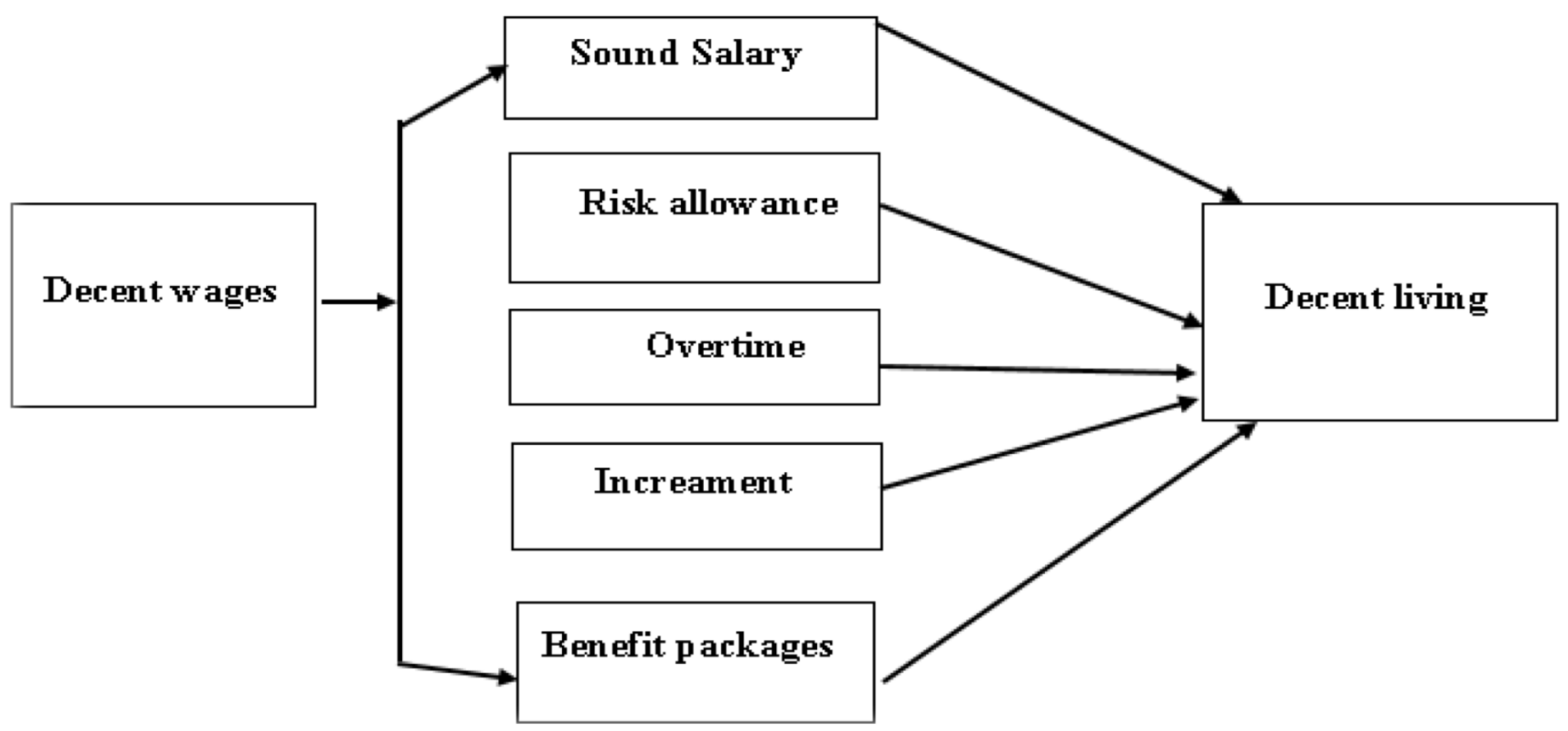

Figure 3: Decent wages

\section{Liveries}

(Own Research, 2020)

Liveries are special safety uniforms which are worn by company employees. Security guards in SubSaharan Africa are not provided with safety liveries needed to safely execute their duties. They are exposed directly to extreme weather conditions when operating outside premises. Security firms 
Tayali, E. M., \& Sakyi, K. A. (2020). The Health and Well-being of Low Paying Jobs in Southern Africa: Case Study of Security Guards in Zambia.

Advances in Social Sciences Research Journal, 7(4) 229-247.

do not provide essential clothing such as raincoats and safety boots to their employees even though they charge heavy amounts to their clients. Therefore, their employees end up having common colds and pneumonia. This affects the physical health of security guards. Safety clothing for security guards is essential for their well-being. Liveries and safety clothing are intra-mural, obligatory and mandatory welfare facilities which employees have to have access to. Security guards end up buying liveries for themselves from the little income they are given.

\section{Protective equipment}

Equally important are safety equipment which are intra-mural welfare facilities that are mandatory for a security guard to have to be effective at work. Working in high crime areas demands one to have protective equipment for self-defense. However, this is not the case for security guards in Zambia and Southern Africa at large.

Security guards are made to guard premises without basic protective equipment such as guns, which they can use for self-defense. This puts the security guards at a high death risk.

\section{Supportive management}

A supportive management system is of essence to employee wellbeing because it guarantees a safe and caring work environment (De Simone, 2014). Security guards in Sub-Saharan Africa are exposed to harsh treatment by management. They are micro-managed, disrespected and harassed. Having a non-supportive management in place at work demotivates employees. This affects employee job satisfaction; as such, employees are not motivated to work hard. This greatly affects their well-being and lowers their self-esteem. The management style in Zambian security firms is one characterized by non-equality, with a high-power distance.

\section{Supportive management from the moral principle of Ubuntu}

Ubuntu is a Bantu word and concept which means the philosophy of humanity for others (Bhengu, 2018). Ubuntu leadership is a practice of human dignity, justice and compassion for employees. A manager is not a manager if he has no humanity for others. Extra-mural and Intra- mural welfare facilities come about from managers with good humanity. There is no Ubuntu principle amongst the managers who expose employees to poor working conditions.

In Zambia, security guards receive a monthly wage of the equivalent of $\$ 75$ which can be referred to as salvation or subsistence wages. This sad state of affairs shows that there is no spark of care and goodness towards other people who find themselves in dire economic straits. Poor African countries such as Zambia have no state welfare system in place to cater for vulnerable people. There is no state safety net to give dole-outs or unemployment cash support. The African set-up believes in an Ubuntu or collectivist culture of sharing and caring for one another. However, this belief and practice is falling apart as the population increases and the economic hardships bite hard.

Therefore, it is difficult to embrace the practice and philosophy of Ubuntu which professes care for other fellow humans. The philosophy of togetherness (Ubuntu) and oneness was propagated under the First Republic from 1964 to 1991 as Humanism or a Zambian version of socialism. Ubuntu fostered qualities such as respect, peace, equality, truth, honesty, love, and above all, care for others. The lack of Ubuntu in managers in Zambia has led to disrespect, selfishness, and inequality in workplaces. Figure 4 details the typical characteristics of Ubuntu leadership. 


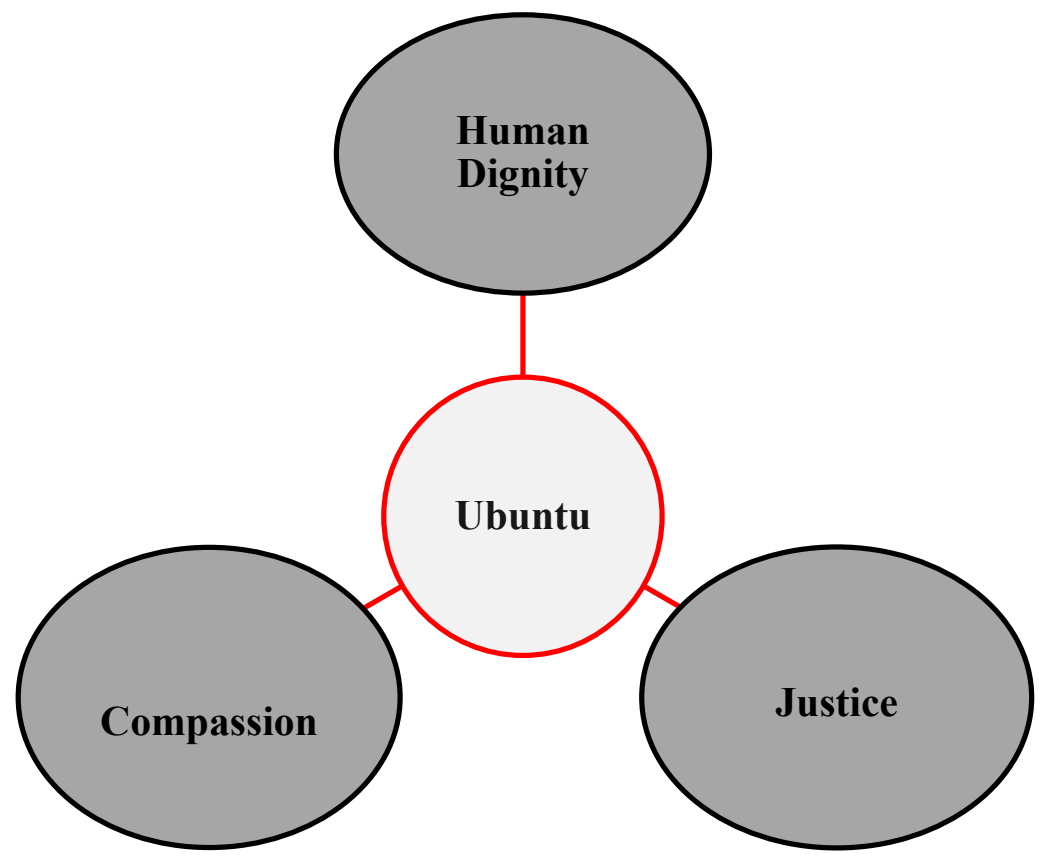

Figure 4: Ubuntu morals

(Source: Tworeck, 2017)

\section{Esteem from the moral principle of Ubuntu}

Adopting the Ubuntu philosophy in management can augment the esteem needs for employees (Tworeck et al, 2017). Respect, appreciation, gratitude, love, support and care are traits of the Ubuntu philosophy which can be used by management in security firms to augment self-esteem for security guards (Karsten, 2017). Society and people around us do play a big role in boosting our self-confidence and making us feel valued. Security guards have low self-esteem because of their economic vulnerability. Because they are looked down upon by society and are less valued by people around them, they tend to become isolated and withdrawn. They are also less valued by their line managers. Their contribution to productivity and profitability are not acknowledged.

Managers and line supervisors who have the Ubuntu attitude towards employees help augment selfesteem in employees. The spark of kindness shown towards security guards by managers brings about their self-esteem. However, management of security firms in Zambia have not shown the Ubuntu principle to security guards. The esteem needs of security guards are not met due to the harsh treatment they receive from management. They are taken for granted and exploited, which borders on some form of commercial slavery.

Many of these security guards do not know their human and natural rights under the labour laws of Zambia, and the international conventions on Human and workers' rights as enshrined in ILO and UN conventions. Figure 5 below provides a diagrammatic form of the hierarchy of welfare needs of security guards in Zambia. When all these needs are met to some appreciable levels, we can state that the Zambian security guard will have reached a state of total happiness that is associated with the ideal states of Utopia, Eudemonism, and well-being. 


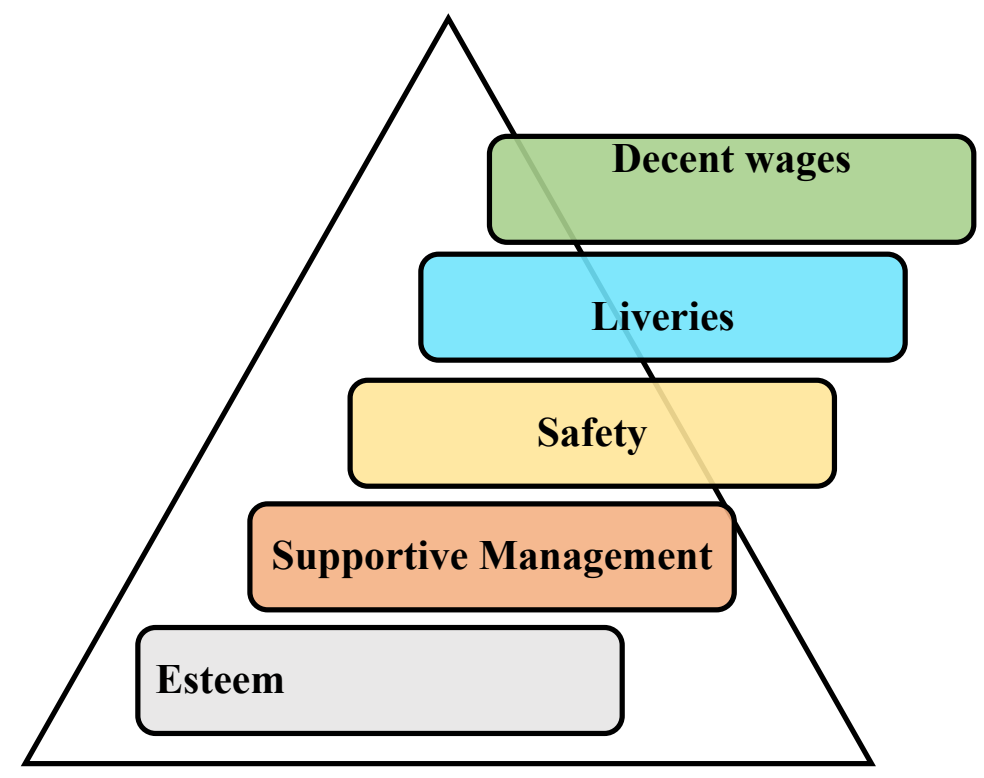

Figure 5: Factors of employee well-being

(Source: Own research, 2020)

\section{Decent working schedules}

Security guards in Zambia begin their first shift from 04:00 a.m. and end at 4:00 pm. The second shift starts from 4:00 p.m. to 4:00 a.m. This has led to a term referred to as "4 to 4". The security guards work six days in a week, and only have a day off. They are not paid any over- time allowance; they only get a monthly fixed salary. The standard working hours for a security guard employee is 48 hours in a week (ILO, 2012). However, in Zambia, the security guards work for 72 hours in a six-day week, thus depriving them of rest and time to be with their families. This all has led to a poor work-life balance. According to CIPD (2016), decent work must have decent working hours and work demands.

\section{Happiness at work}

There are many factors that contribute to happiness at work. These factors have a positive influence on employee well-being (Pryce-Jones, 2010). The word happiness is used because it is more Eudemonic in nature. The happiest employees at work are the best performers (Grant et al, 2007). Happiness at work is the feeling that an employee enjoys work as a result of a healthy work environment, a mindset which allows individuals to heighten performance (Fisher, 2010). Such a conducive and worker-friendly environment is referred to as ergonomic.

\section{Hedonic and Eudemonic Approaches}

According to Fisher (2014), both Eudaimonic and hedonic perspectives are essential to establish a general understanding for a person's well-being. Well-being for security guards can be managed or treated from the perspective of Hedonic and Eudaimonic philosophies. Eudaimonia is a Greek word which means welfare, living well, happiness, and encompassing human prosperity. The word Eudaimon is split into two words, "eu" which means "good" and daimon, which means spirit. 
It is a key concept in Hellenistic philosophy and Aristotelian ethics (Huta, 2015). Hedonism means enjoyment, pleasure, absence of distress and satisfaction. Hedonic aspects include emotions, satisfaction and positive or negative feelings (Huta, 2015).

Henderson (2012) stressed that the Eudaimonic approach brings about happiness to employees because it makes them flourish, and as a result, they become prosperous and they enjoy good living. The use of the hedonic approach in the management of security guards can bring about absence of distress and dissatisfaction for security guards.

\section{Intra-Mural and Extra-Mural welfare facilities for Security Guards}

The structure of welfare and well-being facilities for employees rests on government policy, trade union activism, and the goodwill of employers. Welfare facilities are provided by employers in order to keep employees highly motivated (Suresh, 2015). These welfare facilities have an effect on employee well-being. The fundamental aim of welfare facilities is to keep employees happy and to enrich their lives positively. It connotes a state of well-being, satisfaction, and happiness on the part of employees.

According to Suresh (2015), there are two categories of welfare facilities, namely statutory and nonstatutory. Non-statutory welfare facilities are known as extra-mural, and the statutory welfare facilities are known as intra-mural. The statutory (intra- mural) facilities are compulsory in compliance with labour laws which govern the safety and health of employees. The non-statutory (extra-mural) facilities are initiated by a company or organisation in order to make an employee feel happier, motivated, satisfied and to gain competitive advantage as a preferred company to work for.

The extra-mural facilities differ from one organisation to the other; these may include educational subsidies, assistance programs, health care, and other fringe benefits such as allowances and payment in kind.

Both intra-mural and extra-mural facilities have an effect on the physical, general, and mental health efficiency, and morale of employees. The intra-mural and extra-mural welfare facilities which connote well-being for security guards in southern Africa are detailed in Table 1 below.

Table 1: Intra-Mural and Extra-Mural Welfare Facilities

\begin{tabular}{|c|c|}
\hline Intra-Mural Welfare Facilities & Extra-Mural Welfare Facilities \\
\hline Liveries and Uniforms & Housing allowance \\
\hline Risk allowance & Medical Facility \\
\hline Safety equipment & Education facility \\
\hline Safe working environment & Shift allowance \\
\hline Transport to and from work & Maternity benefit \\
\hline Gratuity & Retrieval and retirement benefits \\
\hline Annual leave & Leave commutation \\
\hline
\end{tabular}

(Source: Guresh, 2015) 
Tayali, E. M., \& Sakyi, K. A. (2020). The Health and Well-being of Low Paying Jobs in Southern Africa: Case Study of Security Guards in Zambia. Advances in Social Sciences Research Journal, 7(4) 229-247.

\section{Social exclusion for Security Guards in Southern Africa}

According to the UN (2018), social exclusion is a multi-dimensional and complex process. It involves denial or deprivation of essentials for well-being such as resources, services, goods and rights. Social exclusion propels one to be socially-excluded from the greater number of people in society, economically, socially, culturally, and politically. This has an adverse effect on the well-being and the quality of working life of people.

The basic paltry wage for security guards exposes them to social exclusion because they are exposed to poverty by being forced to live on $\$ 2.50$ a day. This propels them to belong to a marginalized and minority social group. They are denied access to basic services, activities, resources and opportunities. Furthermore, they have poor access to justice and have little support of the law. They also have little or no say in decision making in society.

They are further excluded from social cohesion, making them to live in isolation, hence they fail to enjoy and reap the benefits of the minimum standards of well-being, whether in the political, social, cultural, and economic arenas of society. The exclusion faced by security guards is categorical, as they are categorized to belong to a certain segment referred to as "minority social group". They are disadvantaged on the basis of their identity. They are therefore vulnerable to negative social behaviours such as drunkenness, petty theft, hard drug abuse, and telling lies.

\section{Social inclusion for security guards}

\section{DISCUSSION}

Social inclusion is a process of improving the ability, conditions, terms and dignity of individuals to enhance their ability to take part in society and enhance their capabilities (Silver, 2015). It involves the process of ensuring that those at poverty risk benefit from the resources and opportunities that are necessary to fully participate in social, economic, political and cultural matters of society. Such a process enables the disadvantaged people to have a stake in decision making. Security guards have little or no voice in their workplaces. There is need to foster an inclusive culture in security firms that will allow security guards to fully participate in dialogue and be able to access different opportunities in the workplace.

Fostering an inclusive culture for security guards in workplaces and society can be accomplished by:

\section{Fostering good income and access equality}

According to the UN (2018) 8\% of people in employment live in extreme poverty. The major cause of poverty is low income, which has an adverse effect on the well-being of people. Income inequality has led to social exclusion for lowly- paid workers such as security guards. Fostering income equality can help create an inclusive culture, reduce poverty, and help eliminate marginalized social groups in society (OECD, 2019). Promoting income equality creates an enabling environment for all employees to fully participate in workplace undertakings. Having equal access to workplace opportunities is also a great way to improve and enhance an inclusive culture.

\section{Introducing trade unions in security firms}

Security firms in Southern Africa have no trade unions and as such, the security guards have little or no voice in their workplaces. Trade unions represent the interests of disadvantaged and poor 
people. Trade unions have collective monopoly power, which they use to negotiate for better conditions for employees to have equal rights and decent wages in workplaces. Without trade unions, poor people and disadvantaged employees such as security guards will remain without voice and they will be treated unfairly.

\section{Developing a well-being strategy}

The well-being of employees on low-paying jobs needs to be addressed at three levels, societal, enterprise and individual levels. This is because different stakeholders are involved. At the societal level, government must provide and enforce statutory policies and laws to promote and protect the well-being of low-skilled workers such as security guards. Correspondingly, employers must comply with the policies, laws and take up the duty to care for the well-being of their employees. In the same way, employees have the responsibility to take care of their own well-being.

\section{The wellbeing of Security Guards as a development perspective}

Living on $\$ 2.50$ a day is close to the datum poverty line as defined by the UN at $\$ 1.90$ a day, a difference of only 60 cents. This categorizes security guards in Zambia as being on the poverty curve. If the wages of security guards are improved, it will help elevate them above the poverty curve. Reduction of poverty among segments of workers can bring about development in Zambia. Security guards like other persons are family men and women with children. Their children are under social exclusion because they cannot access education, decent meals and basic health services at hospitals. Due to lack of decent meals, these children are stunted in growth and are underweight (Borgen Project, 2019).

Their children are not taken to school to acquire education. The conditions under which security guards operate exacerbate poverty, thereby affecting development. Their poor conditions of employment has led and contributed to a lower life expectancy in Zambia, to about 40 years, making it one of the world's lowest expectancy rates (World Population Review, 2020). Sixty per cent of people in Zambia live below the poverty line (Borgen Project, 2019).

\section{Societal Culture -the main cause of poor well-being for Security Guards in Southern Africa} Ethical behaviour by organisations and people has impact on employee well-being; this ethical behaviour is influenced by societal culture (Hofstede, 2004). Societal culture has an impact on organisations and people. There are significant differences on ethical policies amongst organisations and companies in different countries. Using Hofstede's cultural dimensions, a study revealed that companies headquartered in countries where individualism is strong, are more likely to have strong ethical policies, which encourage employee well-being and employee welfare (Cavusgil et al, 2012).

This is opposed to companies headquartered in countries where power distance and masculinity are strong. Countries such as Zambia and Malawi which are strong on power distance are more likely to engage in unethical behaviour which influences the well-being and welfare of employees. Unethical behaviour includes corruption. Corruption is endemic in Southern Africa. The Scandinavian and the UK are strong on individualism. These countries have strong ethical policies and embrace employee well-being. 
Tayali, E. M., \& Sakyi, K. A. (2020). The Health and Well-being of Low Paying Jobs in Southern Africa: Case Study of Security Guards in Zambia.

Advances in Social Sciences Research Journal, 7(4) 229-247.

\section{Religious, non-religious economies and employee well-being}

Sub-Saharan African nations have strong religious beliefs compared to the European and Scandinavian nations. Yet research reveals that Sub-Saharan nations lack value for well-being of employees (Tworeck et al, 2017). In contrast, despite their low religious beliefs, European and Scandinavian nations have much value for well-being of employees (OECD). They promote better life initiatives (OECD, 2018). According to OECD (2018) Sweden is the top performer of well-being as it has pioneered good social policies which value human well-being.

According to the European Commission (2016), one of the biggest areas of interest for European Union is Safety, health and well-being for employees at work. Addionally, Eurofound (2013) also stated that employee well-being and health are of primary importance to the EU and its member states. This shows that Europe has taken keen interest in the health and well-being of people. It is unlike Africa, a religious continent, with less interest in the well-being of people.

The lack of value for employee well-being in Sub-Saharan nations which hold strong religious values denotes an opposite of what religion preaches about value for human well-being. A country like Zambia with strong Christian values is expected to practise strong well-being values. Quite on the contrary, security guards in low-paying jobs in Zambia are less valued and cared for. They work under extreme poor conditions hence they are subjected to poor state of well-being.

\section{Philanthropic theory and well-being}

The Philanthropic theory refers to affection for humankind (Choudherg, 2017). This theory emphasizes on the need to provide good working conditions for employees, just out of affection for humankind. Employees can have better working conditions if we have affection for them. (cf. Robert Owen's Larnark Experiment of Utopia)

\section{Functional theory and well-being}

The other name for functional theory is efficiency theory. This theory emphasizes on the need for the employer to provide employees with welfare equipment and facilities to enhance employee performance, safety, and company efficiency. According to the functional theory, workers must be clothed, fed, and provided with adequate machinery or equipment. Providing workers with adequate facilities increases their efficiency and improves their well-being.

\section{CONCLUSIONS}

There is little or no concern for the well-being of security guards in Zambia. Countries in SubSaharan Africa have not taken interest in the well-being of people in low-paying jobs. There are no laws to protect and enhance the well-being of security guards. If at all there are any laws, it means the laws are silenced as a result of corruption. Due to the poor terms and conditions of employment, security guards are subjected to social exclusion. The voice of a security guard is silenced because of the poor employment conditions and their lack of representation in trade unions.

The well-being of security guards can be enhanced by providing them with decent wages, liveries, safety equipment, and a supportive management. The study reveals that the Zambian national cultures as well as organizational culture do have influence on employee well-being. It is surprising that a religious country such as Zambia has little or no concern for the well-being of its people while not-too-religious nations like Sweden have great concern for the well-being of people. The moral 
of Ubuntu in Southern Africa is not seen being practised today. There is need to exhibit human dignity, justice and compassion towards employees. The low well-being of security guards in low paying jobs has led to low life satisfaction. If the well-being of security guards is improved, it will be seen to be a means to enhance national development and to advance the cause of social inclusion.

\section{References}

Borgen project. (2019). Facts about Poverty in Zambia. Available at:

https://borgenproject.org/10-facts-about-poverty-in-zambia [Accessed: 31 March 2020].

Cavusgil S.T, Knight G., \& Risenberger J. R. (2012). International Business: The New Realities.

New Jersey: Pearson Education.

Chen, P. Y., \& Cooper, C. L. (Eds.) (2014). Wellbeing: A Complete Reference Guide, Work and

Wellbeing Vol. 3 Issue 1

Choudhary, S. (2017). Employee welfare: A scheme of wise investment. International Journal of

Advanced Education and Research. Vol. 2 Issue 1 pp. 01-66.

CIPD (2016). Promoting Health and Well-Being in European Workplaces. EU Briefing.

Contract Number CS08. (2012). Between UN Zambia and Armcor Security Limited. Provision

of Comprehensive Security Management Services.

Daily Nation Newspaper (2015) G4 Security guards down tools The Daily Nation Newspaper

May 19, 2015

De Simone, S. (2014). The Affective Component of Workplace Wellbeing in Organizational

Behaviour Studies. American International Journal of Contemporary Research Vol. 4 Issue 9 pp. 38-43.

Dowd, D. (2018). Importance of security officers and the role they play. Business Management.

European Commission. (2016). Health and Safety at Work. Brussels: European. Commission.

Available at: http://ec.eropa.eu/social/main.jsp [Accessed 30 March 2020].

Fisher, C. D. (2014). Conceptualizing and Measuring Wellbeing at Work. In P. Y. Chen, \& C. L.

Cooper (Eds.), Wellbeing: A Complete Reference Guide Work and Well-being Vol. 3 pp. 9-33

John Wiley \& Sons.

Employment Code Act 2019 No. 3 of 2019

EUROFOUND. (2013) Health and well-being at work: a report based on the fifth European

Working Conditions Survey. Executive summary [online]. Dublin: Eurofound. Available

at:http://www.eurofound.europa.eu/publications/executive-summary/2013/working-conditions/health-and-wellbeing-at-work-executive-summary [Accessed 10 March 2020].

Fisher, C. D. (2010). Happiness at work. International Journal of Management Review Vol. 12

pp. 384-412.

Gough, K.V., Chigunta, F. \& Langevang, T. (2016) Expanding the scales and dimensions of

(in)security- Youth employment in urban Zambia Environment and Planning A- Sage

Journals 2016 Vol. 48 Issue 2, pp.348-366

Grant, A. M., Christianson, M. K., \& Price, R. H. (2007). Happiness, health, or relationship? 
Tayali, E. M., \& Sakyi, K. A. (2020). The Health and Well-being of Low Paying Jobs in Southern Africa: Case Study of Security Guards in Zambia. Advances in Social Sciences Research Journal, 7(4) 229-247.

Managerial practices and employee well-being trade-off. Academy of Management

Perspective Vol. 21 pp.51-63

Gunwan, H. \& Amalia, R. (2015) Wages and employees performance: The quality of work life as moderator International Journal of Economics and Financial Issues Vol. 5 Special Issue pp. 349-353

Henderson, L. (2012), Integrating the Hedonic and Eudemonic perspectives to more comprehensively understand well-being and pathways to wellbeing Journal?

Hofstede, G.H., (2004). Culture's Consequences: International Differences in Work-Related Values

(Revised Edition). Thousand Oaks, CA: Sage Publications

Huka V. (2015) An overview of Hedonic and Eudaimonic well-being concepts.

Health and safety authority (2008). Workplace Health and Well-being Strategy Report of Expert Group.

ILO (2019) Future of work- The Zambian Experience

ILO (2012) Decent Work Country Profile Zambia (2012)

Nick, L. \& Lings, I., (2008) Doing Business Research. A guide to theory and practice London:

SAGE Publications Limited.

IMF Country Report (2006) Zambia Poverty Reduction Strategy Paper (ZPRSP) - $5^{\text {th }}$

Development Plan

Karsten, L. (2017) Ubuntu as a Key Management Concept. Research Gate Publications. Mywage.org Security Guards [Online] mywage.org_Zambia.htm

Nyirenda, E. J., Sikazwe, A. (2003) Trade Union Country Report-Zambia Freidrich Ebert

\section{Foundation}

OECD (2019) Implementing social protection strategies. Lessons from European Union Social

Protection Strategies.

OECD Better Life Initiative (2018). How is life in Sweden? Sweden's Current Well-Being. Saunders, M., Lewis, P. \& Thornhill, A. (2012). Research Methods for Business Students 6th edition, Pearson Education Limited.

Simone, S. (2014). Conceptualizing well-being in the workplace. International Journal of Business and Social Science. Vol.5(12), pp 44-48

Silver, H. (2015) Contexts of social inclusion. Department of economic and social affairs Suresh, G. (2015). Intra mural and extra mural welfare facilities provided by neyvelignite cooperation limited. International Journal of World Research. Vol. 1 Issue 20 pp. 26-30.

United Nations (2018) Sustainable Development Goals

Tworeck, C., Hemminga, D. and Dhillon, D. (2017) The Ubuntu Philosophy as a Management

Strategy. Research Gate.

United Nations Development Programme (2013) Humanity Divided: Confronting Inequality in Developing Countries 
United Nations (2006) Social Justice in an Open world International Forum for Social

Development. New York

UN Zambia (2012) Contract No. CS08- 12/2012 between UN Zambia and Armcor Security

Limited for the provision of comprehensive security management services for the UNO in Zambia

Valentine, T.R. (2002) Medium term strategy for enhancing pay and conditions of service in the

Zambian public service Government of Zambia Commissioned Report from Crown Consultants International

World Bank (2018) Republic of Zambia Systematic Country Diagnostic World Bank March

2018

World Population Review. (2020) Life Expectancy 2020. Available at:

https://worldpopulationreview.com/countries/life-expectancy-by-country/ [Accessed 31 March 2020 ].

Zambia Daily Mail (2014) Security guards most neglected workers Zambia Daily Mail

Newspaper August 30, 2014

\section{Notes}

The funding for this paper came out of the personal income of the authors.

\section{Acknowledgement}

We wish to thank our families and friends who put up with us whilst pounding at this job. We thank you for your moral support and encouragement. We also thank our mentors who made sure we did the right things. Thank you all. 